\title{
Human Endometrial Regenerative Cells Attenuate Bleomycin-Induced Pulmonary Fibrosis in Mice
}

\author{
Yiming Zhao $\mathbb{D}^{1,2}$ Xu Lan $\mathbb{D}^{1,2}$, Yong Wang, ${ }^{3}$ Xiaoxi Xu $\mathbb{D}^{4},{ }^{4}$ Shanzheng $\mathrm{Lu},{ }^{5}$ Xiang Li, ${ }^{1,2}$ \\ Baoren Zhang $\mathbb{D}^{1,}{ }^{1,2}$ Ganggang Shi, ${ }^{6}$ Xiangying Gu, ${ }^{7}$ Caigan $D u\left(\mathbb{D},{ }^{8,9}\right.$ and Hao Wang $\mathbb{D}^{1,2}$ \\ ${ }^{1}$ Department of General Surgery, Tianjin Medical University General Hospital, Tianjin, China \\ ${ }^{2}$ Tianjin General Surgery Institute, Tianjin Medical University General Hospital, Tianjin, China \\ ${ }^{3}$ Department of Ultrasonography, National Cancer Center/Cancer Hospital, Chinese Academy of Medical Sciences and Peking Union \\ Medical College, Beijing, China \\ ${ }^{4}$ Department of Endocrinology and Metabolism, Tianjin Medical University General Hospital, Tianjin, China \\ ${ }^{5}$ Department of Anorectal Surgery, People's Hospital of Hunan Province, First Affiliated Hospital of Hunan Normal University, \\ Changsha, Hunan, China \\ ${ }^{6}$ Department of Colorectal Surgery, The Second Hospital of Tianjin Medical University, Tianjin, China \\ ${ }^{7}$ Department of Gynecology and Obstetrics, Tianjin Medical University General Hospital, Tianjin, China \\ ${ }^{8}$ Department of Urologic Sciences, The University of British Columbia, Vancouver, BC, Canada \\ ${ }^{9}$ Immunity and Infection Research Centre, Vancouver Coastal Health Research Institute, Vancouver, BC, Canada
}

Correspondence should be addressed to Hao Wang; hwangca272@hotmail.com

Received 23 December 2017; Revised 7 March 2018; Accepted 24 May 2018; Published 25 July 2018

Academic Editor: Yun Zhao

Copyright (C) 2018 Yiming Zhao et al. This is an open access article distributed under the Creative Commons Attribution License, which permits unrestricted use, distribution, and reproduction in any medium, provided the original work is properly cited.

\begin{abstract}
Endometrial regenerative cells (ERCs) have been recently evaluated as an attractive novel type of stem cell therapy. Previous studies have demonstrated that most ERCs accumulated in the lung after injection and are successfully used to treat diseases such as cardiac fibrosis. However, relevant studies of ERCs in idiopathic pulmonary fibrosis (IPF) have not been reported. The present study was designed to examine the effects of ERCs on bleomycin-induced pulmonary fibrosis. All IPF models in C57BL/6 mice were induced by administrating $5 \mathrm{mg} / \mathrm{kg}$ bleomycin in PBS intratracheally. ERCs were isolated from healthy female menstrual blood and were injected (1 million/mouse, i.v.) 24 hours after induction. Wet/dry weight ratio assay, hydroxyproline content, pathological and immunohistological changes, MDA content, T-SOD activity, cytokine profiles, and RT-qPCR analysis were assessed 2 weeks after disease induction. The results showed that ERC treatment significantly decreased the wet/dry ratio and reduced collagen deposition. Histological analyses, Masson staining, and hydroxyproline content analysis indicated that ERCs could reduce collagen fiber production. Immunohistochemical staining revealed lower expression of TGF- $\beta$ after ERC treatment. Furthermore, mice treated with ERCs had lower levels of IL- $1 \beta$ and TNF- $\alpha$, but a higher level of IL-10 in both the lung and serum. Gene expression analysis demonstrated that ERCs potently suppressed the proapoptotic gene Bax, while increasing the antiapoptotic gene Bcl-2 and antifibrosis genes HGF and MMP-9. Our results indicate that human ERCs protected the lung from pulmonary fibrosis in mice through immunosuppressive and antifibrosis effects. Moreover, these findings formed a foundation for the further use of ERCs in clinical treatment.
\end{abstract}

\section{Introduction}

Idiopathic pulmonary fibrosis (IPF), the most common form of the idiopathic interstitial pneumonias, is a chronic, progressive, irreversible, and usually lethal lung disease of unknown cause [1]. Due to no curative therapeutic options to halt disease progression and the lack of understanding of the pathogenic initiators and drivers [2], IPF becomes a most life-threatening disease with median survival time of around 2.5 to 3.5 years after diagnosis [3].

A recently held theory about the pathophysiology of IPF suggested association with oxidative stress, hyperplasia, 
denudation, and apoptosis of type II alveolar epithelial cells (AEC II) might be a primary cause of this process $[4,5]$. Multiple alveolar injuries were regarded to be the initiator of IPF development. Injured epithelial cells release numerous mediators which not only interfere with the microenvironment of the lung but can also release a wide range of cytokines, chemokines, and growth factors, such as interleukin-1 beta (IL-1 $\beta$ ), C-C motif chemokine ligand-2 (CCL2), and transforming growth factor- $\beta$ (TGF- $\beta$ ) $[6,7]$. Among those, TGF- $\beta$ plays a central role through inducing myofibroblast accumulation, enhancing extracellular matrix synthesis, and promoting the epithelial mesenchymal transition (EMT) $[8,9]$. Currently, two drugs, pirfenidone and nintedanib, were approved by the FDA for clinical use as they were able to slow down the disease progression. Among which, pirfenidone is an antifibrotic, anti-inflammatory, and antioxidant molecule which inhibits TGF- $\beta$-induced collagen synthesis $[10,11]$.

Mesenchymal stem cells (MSCs) have been recently reported as an emerging therapy for prevention of multiple lung diseases $[12,13]$. Previous studies have shown that MSCs home to the sites of injury lung, inhibiting production of proinflammatory mediators, attenuating deposition of extracellular matrix, repairing epithelial tissues, and generally contributing to structural stability [14-16]. Besides that, MSCs also secreted different types of soluble factors via a paracrine mechanism to exert antiapoptosis, anti-inflammation, and antifibrosis characteristics [17, 18]. After many years of investigation, MSCs have been used in clinical treatment to treat IPF and exerted relatively curative effect [19]. However, there are still some restrictions such as the invasive acquire access, promoting tumor growth [20] and increasing the metastatic potency of cancer cells [21] in the process of MSC treatment.

Endometrial regenerative cells (ERCs), a novel type of adult stem cells derived from human menstrual blood, were first reported by Meng et al. in 2007 [22]. This new source of stem cell possesses the following advantages over conventional stem cells such as having plenty of sources, being easy access to obtain, having strong proliferation capacity, having the ability to differentiate into three germ layers in specific induction media, being able to promote tissue repair, and having the capacity to reduce the occurrence of immune rejection as a result of autologous cells transplantation [23-25]. We and others have founded that ERCs were effective in preventing critical limb ischemia [23], prolonging of the cardiac allograft survival [24], reducing renal ischemia reperfusion injury [25], and attenuating experimental colitis [26], burn injury [27], acute liver injury [28], and acute lung injury [29]. It is worth mentioning that ERCs have been investigated for the treatment of acute respiratory distress syndrome (ARDS) and located in lung tissue by the action of chemokines [29].

However, whether ERCs could be feasible for antiapoptosis, anti-inflammation, and antifibrosis in IPF remains obscure. The present study was designed to explore the effect of human ERCs on attenuating bleomycin-induced pulmonary fibrosis in mice.

\section{Materials and Methods}

2.1. ERC Collection, Isolation, and Culture. The isolation of ERCs was prepared according to the methods described previously $[30,31]$. Briefly, after approval by the ethics committee and obtaining informed consent, ERCs were isolated from menstrual blood of healthy female volunteer donors (20-40 years old) on the first day of menstruation using a menstrual cup. Mononuclear cells from menstrual blood were separated by using a standard Ficoll method and then suspended in Dulbecco's modified Eagle's medium (DMEM) high glucose supplemented with $1 \%$ double antibiotics (penicillin/streptomycin) and 10\% fetal bovine serum (FBS). The resultant cells were seeded in $10 \mathrm{~cm}$ dishes cultured in a humidified incubator at $37^{\circ} \mathrm{C}$ in $5 \% \mathrm{CO}_{2}$. Nonadherent cells were removed by rinsing cells with culture medium, and ERCs were adhered to plastic dishes showing spindle-shaped morphology. When ERCs reached $80 \%$ confluence, they were routinely passaged using $0.25 \%$ trypsin and fourth-passage cells were used for the experiments.

2.2. Animals. Naive female C57BL/6 mice (Aoyide Co., Tianjin, China) weighing $18-20 \mathrm{~g}$ and aged 6-8 weeks were used. Animals were maintained under constant temperature and humidity conditions with a 12:12 light-dark cycle in the animal care facility of Tianjin General Surgery Institute (Tianjin, China) and had free access to standard chow and drinking water. All the experiments with animals were conducted in accordance with the protocols approved by the Animal Care and Use Committee of Tianjin Medical University (Tianjin, China) according to the Chinese Council on Animal Care guidelines.

2.3. Experimental Groups. IPF in mice was induced as previously described $[32,33]$. In brief, 18 mice were randomly divided into three groups $(n=6)$ as follows:(1) sham control group: after intraperitoneal anesthesia with $10 \%$ lidocaine, mice were operated by opening and closing the skin and tissue in front of the trachea without intratracheal injection; (2) untreated group: each C57BL/6 mouse was intratracheally administered $5 \mathrm{mg} / \mathrm{kg}$ bleomycin sulfate (Beijing Solarbio Science \& Technology Co. Ltd., Beijing, China) dissolved in sterile PBS in $50 \mu \mathrm{l}$ volume for induction of pulmonary fibrosis. 24 hours later, $200 \mu \mathrm{l}$ PBS was injected via the tail vein; and (3) ERC-treated group: IPF in mice was induced in the same manner as ahead. One million ERCs suspended in $200 \mu \mathrm{l}$ of PBS were injected via the tail vein 24 hours after disease induction. All mice were sacrificed on day 14 after BLM induction, and blood was obtained via the abdominal aorta. The lung was then removed for analysis or stored frozen at $-80^{\circ} \mathrm{C}$.

2.4. Wet/Dry Weight Ratio Assay. The wet/dry (W/D) measurement was used to detect pulmonary edema. After a thoracotomy, the right inferior lobar lungs were collected and weighed immediately to determine the wet weight. Then, putting the lung tissues into the incubator at $60^{\circ} \mathrm{C}$ for 24 hours, the dry weight was recorded. 
2.5. Collagen Content Assessment by Hydroxyproline Assay. Hydroxyproline (HYP) assay was used to measure the collagen content in the lung homogenates using a commercially available kit (Nanjing JianCheng Bioengineering Institute, Nanjing, China). The experimental procedure was performed in accordance with the protocols provided, and the absorbance of each sample was read at $550 \mathrm{~nm}$ by a microplate reader. Assuming that collagen contains an average of $13.5 \%$ hydroxyproline [34], the data were expressed to quantitatively analyze the collagen content in lung tissue.

2.6. Histological Examination and Masson's Trichrome Staining. The left lungs were fixed with $10 \%$ formalin for $48 \mathrm{~h}$ and underwent the process of dehydration, paraffin embedding, and sectioning. The $5 \mu \mathrm{m}$ thickness sections were stained with hematoxylin and eosin (HE) and Masson's trichrome stain for collagen deposition according to standard protocols. According to classical Masson staining, collagen fibers are stained blue and nuclei are dyed black, while cytoplasm and muscle are dyed red.

The severity of lung fibrosis was assessed by measuring the Ashcroft score [35] for semiquantitative analysis of histological fibrotic changes. Each section was observed in 5 fields of view, and the average score of fibrosis ranging from 0 (normal lung) to 8 (total fibrous obliteration of the field) was used to evaluate [36].

2.7. Immunohistochemistry. To evaluate engraftment of TGF$\beta 1$, the paraffin specimens were cut into $5 \mu \mathrm{m}$, following by dewaxing and rehydration. Tissue sections were incubated with $3 \% \mathrm{H}_{2} \mathrm{O}_{2}$ to block endogenous peroxides, and antigen retrieval was processed by heating in a microwave. After enclosed by $5 \%$ bovine serum albumin (BSA), the specimens were stained with rabbit anti-mouse TGF- $\beta 1$ polyclonal antibody (Abcam, Shanghai, China) and goat anti-rabbit IgG polyclonal antibody sequentially. And then horseradish peroxidase-conjugated avidin and brown-colored diaminobenzidine were used to visualize the labeling. Finally, the slides were restained with hematoxylin and mounted.

2.8. Measurement of Total Superoxide Dismutase (T-SOD) Activity and Malondialdehyde (MDA) Content. Partial lung tissues of each group frozen in $-80^{\circ}$ were collected and homogenized and then centrifuged for 10 minutes at $3000 \mathrm{rpm}$ at $4^{\circ}$. The supernatant was extracted and tested for T-SOD activity and MDA content. The procedures used to quantify T-SOD activity and MDA content were conducted according to the manufacturer's instructions (Nanjing Jiancheng Bioengineering Institute, Nanjing, China). The absorbance changes at 550 and $532 \mathrm{~nm}$ were monitored.

2.9. ELISA. Supernatants of homogenized lung tissues and serum were used to measure the levels of IL- $1 \beta$, TNF- $\alpha$, and IL-10. Conducted by the ELISA kit protocol (eBiosciences, San Diego, CA, USA), each sample was added into two wells to eliminate the error, followed by methods of double-antibody sandwich, biotin amplification system, and horseradish peroxidase catalytic substrate. The reaction was terminated by addition of acid and absorbance was measured at $450 \mathrm{~nm}$. The concentration of each sample was obtained by comparing the sample and the standard curve.

2.10. RT-qPCR Analysis. Total RNA was extracted from lung tissue using an animal tissue RNA extraction kit (DP431, Tiangen Biotech Co. Ltd.). The extracted RNAs were reverse transcribed into cDNAs by using a FastQuant RT kit with gDNase (KR106, Tiangen Biotech Co. Ltd.). The purity and quality of the RNA were examined with an UV spectrophotometer at 260 and $280 \mathrm{~nm}$. To assess the expression of target genes, quantitative real-time PCR was performed using SuperReal Color PreMix (FP216, Tiangen Biotech Co. Ltd.) according to the manufacturer's instruction. Sequences of the mouse gene-specific primers used were listed as follows: $\beta 1$-actin: forward, AGACAG GGGCCTTTTTGCTAC, reverse, AATTCGCCGGAGAC ACTCG; Bax: forward, AACAGGGGCTTTACGTTCACT, reverse, CGTCCCTTTATAGCTGCCTCC; Bcl-2: forward, AGCCCTGTGCCACCATGTGTC, reverse, GGCAGGTTT GTCGACCTCACT; HGF: forward, AACAGGGGCTTTAC GTTCACT, reverse, CGTCCCTTTATAGCTGCCTCC; MM P-9: forward, GGACCCGAAGCGGACATTG, reverse, CGT CGTCGAAATGGGCATCT. The relative expression of the target gene was analyzed using the comparative $2^{-\Delta \Delta \mathrm{CT}}$ method.

By subtracting the $\mathrm{Ct}$ value of $\beta$-actin from that of the target gene, we obtained $\triangle \mathrm{Ct}$, whereas $\triangle \triangle \mathrm{Ct}$ was calculated by subtracting the value of $\triangle \mathrm{Ct}$ from that of the sham control sample.

2.11. Statistical Analysis. Statistical analysis was performed in SPSS 22.0. All data were presented as mean \pm standard error of the mean (SEM). The data obtained from the sham control group, untreated group, and ERC-treated group were compared using one-way analysis of variance (ANOVA), following by the independent-samples $t$ test to analyze parametric data. Differences with $p$ values of less than 0.05 were considered statistically significant.

\section{Results}

3.1. ERCs Ameliorate Alveolitis and Abrogate Collagen Deposition in Lungs. It has been observed that on-going AEC injury in the lungs and aberrant repair mechanisms have been implicated in the pathogenesis of IPF. We have investigated whether human ERCs (which exhibit immunomodulatory properties) have therapeutic effects on inhibiting pulmonary fibrosis in a mouse model and found that the lung in the untreated group became inflamed and mauve and had fibrous deposition under macrography (Figure 1(a)), suggesting that bleomycin had induced severe pulmonary fibrosis. Whereas, the lung structural changes in the ERC-treated group possessed a significant relief by contrast, which were not significantly different from those in the sham control group (Figure 1(a)). In addition, wet/ dry weight ratios were calculated to evaluate the pulmonary edema caused by the inflammatory responses. As anticipated, there was no significant difference in the ratios between the ERC group and sham control group. In 


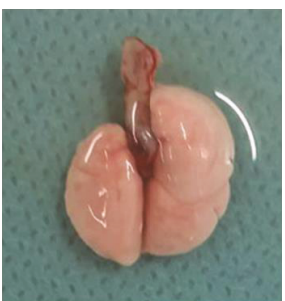

Sham control

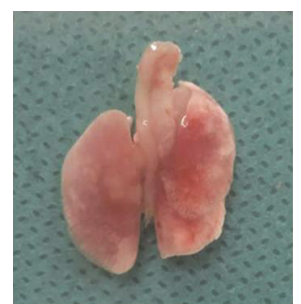

Untreated

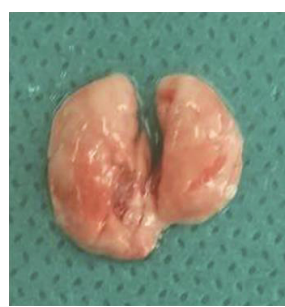

ERC treated (a)

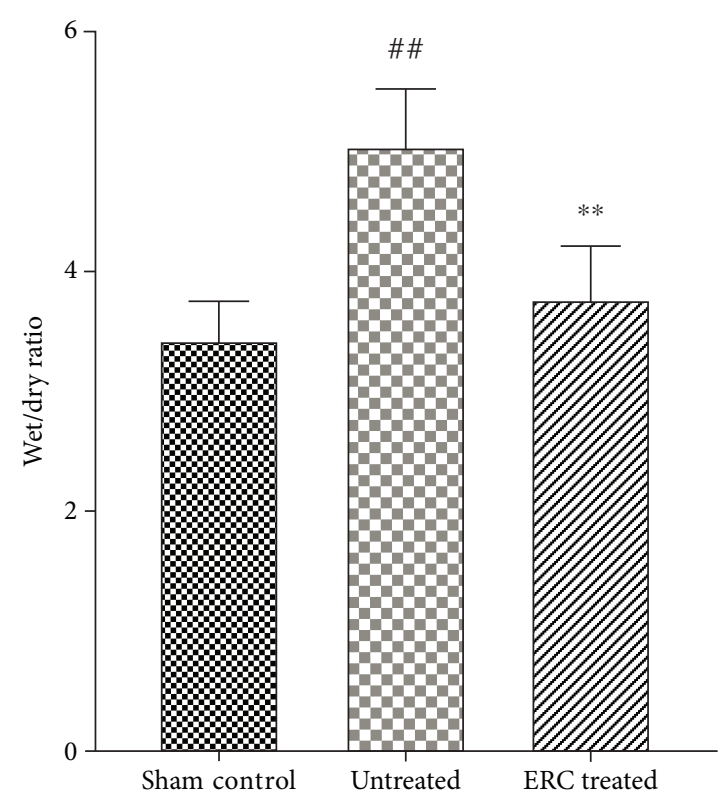

(b)

FIGURE 1: ERCs ameliorate alveolitis and abrogate collagen deposition. (a) Representative figure of gross pathology. The lung in the sham control group presents as complete and smooth, while in the untreated group became inflamed and mauve and had fibrous deposition. After ERC treatment, it showed the reverse of the inflammation and partial fibrotic patches. (b) Wet/dry ratio evaluates the pulmonary edema which represents the severity of inflammation. ERCs reduced the level of wet/dry ratio in comparison with that of the untreated group. Bar graphs represent mean \pm SEM of three separate experiments. $p$ values were determined by one-way ANOVA. Data shown are representative of three separate experiments performed. (\#\# $p<0.01$ versus the sham control group. ${ }^{* *} p<0.01$ versus the untreated group, $n=6)$. ERCs: endometrial regenerative cells.

contrast, the ERC group showed notably less pulmonary edema than the untreated group (Figure $1(\mathrm{~b}), p<0.01$ ). The results suggested that transplantation of ERCs could attenuate the levels of the inflammation by reducing pulmonary edema.

3.2. ERCs Modulate Cell Infiltration, Inflammatory Response, and Extracellular Matrix Remodeling in the Lungs. To more specifically study the lung injury, we examined detected histopathological changes of the lungs in different groups. As shown in Figure 2(a), the alveolar structure in the sham control group was clear and complete. Whereas, in the untreated group, the normal alveolar structure disappeared, characterized by the presence of extensive mesenchyme expanded with increased numbers of inflammatory cells, and there even exhibited a majority of consolidation in the lung (Figure 2(a)). Compared with the untreated group, after ERC treatment, the inflammatory cell infiltration and the interstitial fibrosis formation were markedly reduced. Even though there were still little interstitial hyperplasia, the alveolar structure remained complete. In addition, Ashcroft's scores were performed in a blinded fashion to quantify lung damage (Figure 2(b), $p<0.01$, the untreated group versus the ERC-treated group), which correlate with the pathological changes of the lung tissues.

3.3. Localization and Quantitative Detection of Fibrous Tissue Changes in the Lung. To investigate the location and content of fibrous tissue changes in the lung, we performed Masson staining on each group. As shown in Figure 3(a), a few collagenous fibers (blue staining) were presented in the sham control group without the presence of interstitial fibroplasia. With regard to the untreated group, a large quantity of collagenous fibers was observed (Figure 3(a)), whereas, after ERC treatment, the collagen fiber production reduced. Meanwhile, the interstitial hyperplasia and alveolar structural damage were significantly decreased in the lungs. To further verify our findings, we determined the level of lung hydroxyproline, a major component of collagen which contains an average of $13.5 \%$. In the untreated group, hydroxyproline content (Figure 3(b)) was significantly higher than that in the sham control group $(p<0.01)$. However, the content was decreased after ERC treatment (Figure 3(b), $p<0.01$, the untreated group versus the ERC-treated group). These findings suggested that ERCs could reduce production of fibers and promote recovery of fibrosis in the lung.

3.4. ERCs Reduce the Expression of Initiation Factor TGF- $\beta$ in Promoting Fibrosis. Subsequently, we attempted to ascertain the ability of ERCs to inhibit lung fibrosis and to study whether its underlying mechanism was associated with the vital factor TGF- $\beta$, which functions as a central regulator in promoting fibrosis. We intuitively tested its expression level in lung tissue by immunohistochemistry. As shown in Figure 4 , high density of TGF- $\beta$ staining was detected in the untreated group. In sharp contrast, remarkably weaker TGF- $\beta$ staining was found in lung tissue of the ERC-treated group, which was indistinguishable from that of the sham control group. This finding demonstrated that treatment 


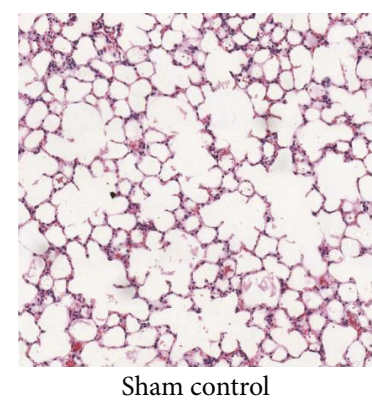

Sham control

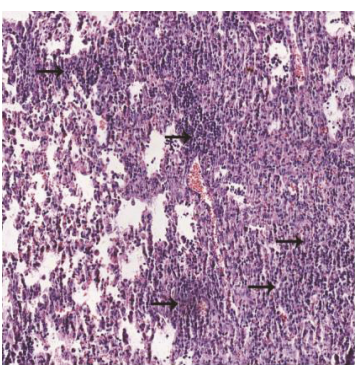

Untreated

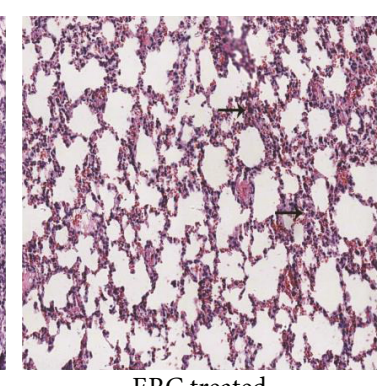

ERC treated

(a)

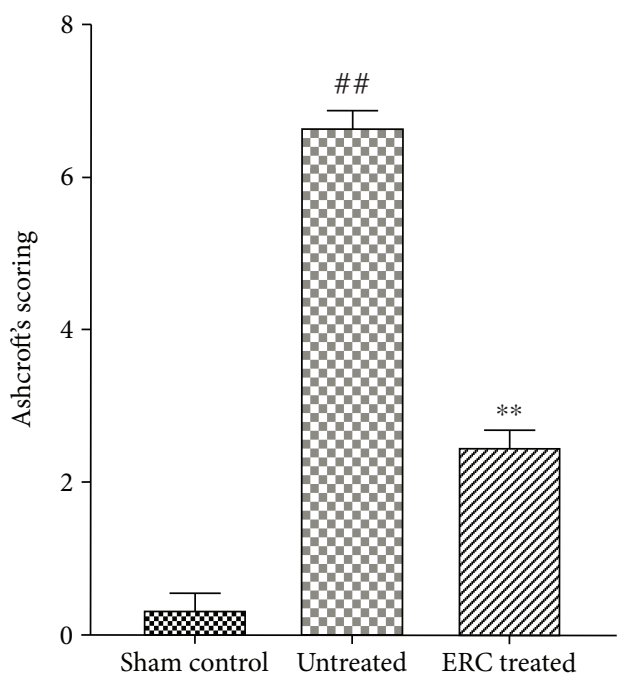

(b)

FIGURE 2: ERCs significantly attenuate pathological damage induced by BLM in mice. (a) Representative section of different groups of the lungs (200x magnification, HE staining). The lungs in the untreated group exhibited more cell proliferation, inflammatory response, and extracellular matrix remodeling than those in the normal control groups, whereas, there was a marked remission in the ERCtreated group. (b) Quantitative assessment of lung damage was performed according to Ashcroft's scores. Values represent mean \pm SEM. ${ }^{\# \#} p<0.01$ versus the sham control group. ${ }^{* *} p<0.01$ versus the untreated group, $\left.n=6\right)$. ERCs: endometrial regenerative cells; BLM: bleomycin.

with ERCs might alleviate pulmonary fibrosis by decreasing the secretion of TGF- $\beta$.

3.5. ERC Treatment Improves the Antioxidant Capacity of the Lung Tissue. Total superoxide dismutase (T-SOD) plays an important role in the oxidation and antioxidant balance of the organism. The enzyme can scavenge superoxide radicals and protect cells from injury. The amount of malondialdehyde (MDA) reflects the extent of lipid peroxidation in the body and indirectly reflects the extent of cell damage. As shown in the result, T-SOD activity in the lung tissue from the ERC-treated group was significantly increased compared to that from the untreated group $(p<0.01$, Figure 5), whereas, the amount of MDA in ERC-treated group was markedly lower than that in the untreated group $(p<0.01$, Figure 5). Thus, the data suggested that treatment with ERCs might attenuate the oxidative stress in pulmonary fibrosis.

3.6. ERC Treatment Delays the Fibrosis Progress by Regulating Cytokine Expression. To determine whether ERC treatment could affect cytokine profiles, the levels of local and serum inflammatory cytokines were analyzed and compared among different groups. For the levels of proinflammatory cytokines, we found that the levels of IL- $1 \beta$ and TNF- $\alpha$ in the ERCtreated group were much lower than that of the untreated group in both the lung $(p<0.05$, Figures $6(\mathrm{a})$ and $6(\mathrm{~b}))$ and the serum $(p<0.05$, Figures 6(d) and 6(e)). Meanwhile, the level of anti-inflammatory cytokine IL-10 was elevated after ERC treatment as compared to the untreated group $(p<0.01$, Figures 6(c) and 6(f)). These data indicated that treatment with ERCs may slow down the occurrence of fibrosis by suppressing the level of proinflammatory cytokines and enhancing the level of anti-inflammatory cytokines.

\subsection{ERCs Attenuate Pulmonary Fibrosis by Upregulating} Antiapoptotic and Antifibrotic Factors in the Lungs. To explore the underlying mechanisms of ERCs on alleviating fibrosis, we tested the mRNA levels of several possible targeting factors related to antiapoptosis and antifibrosis. As compared to the untreated group, we found that after treatment with ERCs, the expression of apoptotic factor Bax in the lung tissue was decreased $(p<0.05$, Figure $7(\mathrm{a}))$, 


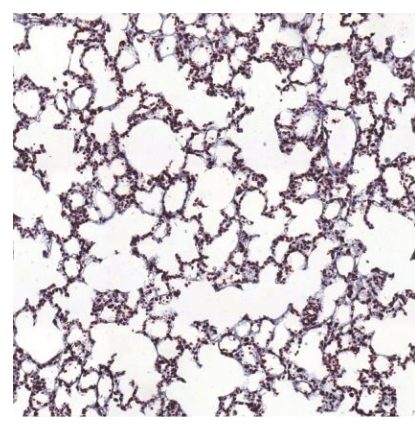

Sham control

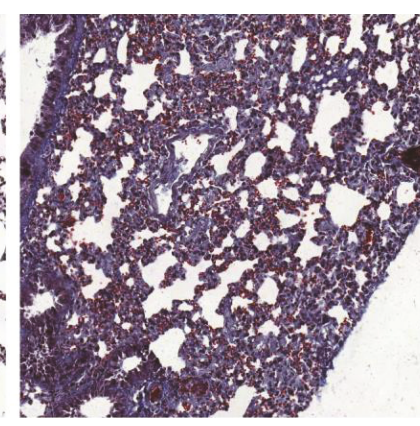

Untreated

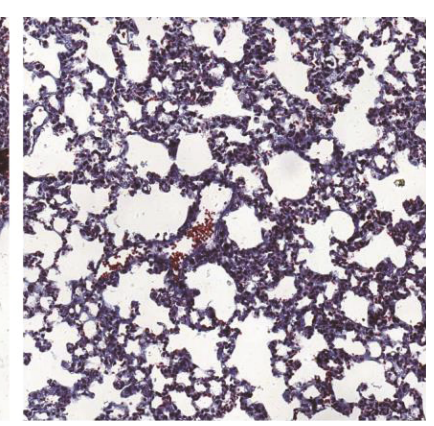

ERC treated

(a)

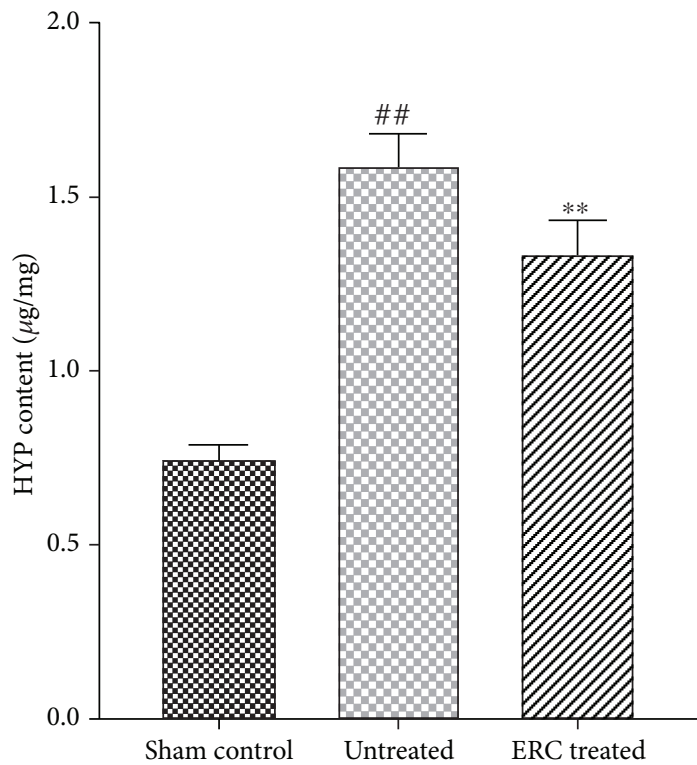

(b)

FIgURE 3: Focus on fibrous tissue changes in the lung. Representative images of Masson staining and hydroxyproline assessment. (a) The ERC-treated group exhibits smaller collagen fiber production, interstitial hyperplasia, and alveolar structural damage than the untreated group (200x, Masson staining). (b) Levels of collagen deposition in the lung are determined by hydroxyproline estimation. On treatment with ERCs, a reduction in levels of hydroxyproline was observed. Values represent mean \pm SEM. (\#\# $p<0.01$ versus the sham control group. ${ }^{* *} p<0.01$ versus the untreated group, $n=6$ ). ERCs: endometrial regenerative cells.

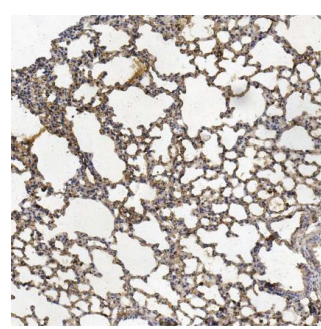

Sham control

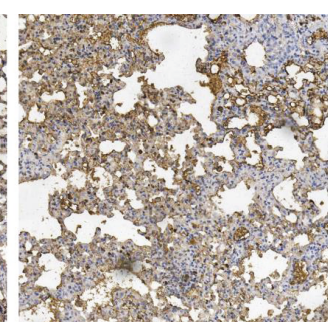

Untreated

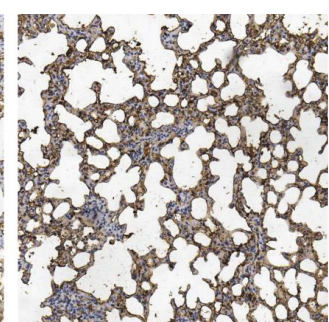

ERC treated

FIGURE 4: ERCs attenuate lung fibrosis by reducing the expression of vital factor TGF- $\beta$. Immunohistochemical result of transforming growth factor-beta $($ TGF- $\beta)(\times 200$ magnification); yellowish-brown staining signifies positive staining of TGF- $\beta$. In the untreated group, TGF- $\beta$ expressed abundantly and mainly deposited on proliferating inflammatory cells and fibrous tissues, while in the ERC-treated group, it can be seen that the TGF- $\beta$ expression is reduced, which is similar to the sham control group. ERCs: endometrial regenerative cells; TGF- $\beta$ : transforming growth factor- $\beta$. 

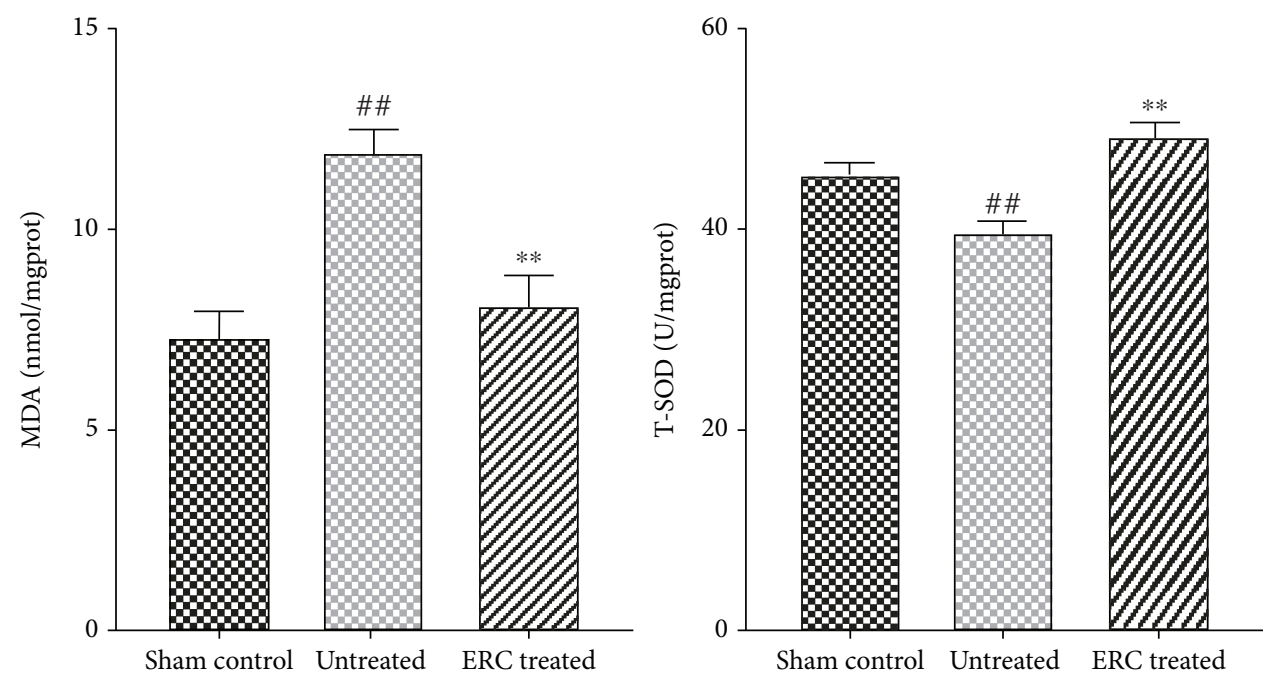

FIgURE 5: ERC treatment improves the antioxidant capacity of the tissue. Pulmonary MDA and T-SOD activity were detected by a colorimetric method. Data revealed that ERC treatment improves T-SOD activity, whereas it reduced the content of MDA in lung homogenate. Values represent mean \pm SEM. (\#\# $p<0.01$ versus the sham control group. ${ }^{* *} p<0.01$ versus the untreated group, $n=6$ ). ERCs: endometrial regenerative cells; MDA: malondialdehyde; T-SOD: total superoxide dismutase.

while the expression of antiapoptotic factor Bcl-2 was significantly increased $(p<0.05$, Figure $7(b))$. In addition, the antifibrosis factors HGF and MMP-9 were also markedly elevated after ERC treatment $(p<0.05$, the untreated group versus the ERC-treated group, Figures $7(\mathrm{c})$ and $7(\mathrm{~d}))$. The above results suggested that ERCs may play an important role in attenuating pulmonary fibrosis by upregulating antiapoptotic and antifibrotic factors.

\section{Discussion}

Idiopathic pulmonary fibrosis is a progressive disease whose incidence and mortality are increasing steadily worldwide $[37,38]$. Currently, there is no effective treatment for this disease. MSCs have been used for scientific research and clinical treatment in search of new and diversified therapies, but invasiveness extraction and the proliferative capacity of MSCs have limited its development [22, 39, 40]. ERCs act as a new autologous source of stem cells and can be obtained in large amounts without karyotypic abnormalities [22]. Moreover, its high proliferation ability and easy access in obtaining provide an adequate source for treatment [24]. It has been reported that ERCs can differentiate into alveolar epithelial cells and secretion of MMP3 and MMP10 at 10100,000-fold higher levels than mesenchymal stem cell lines [22]. Based on the above statement, we designed this study and discovered that ERC treatment is an effective therapeutic measure to alleviate pulmonary fibrosis. We focused on investigating the degree of fibroses by HE staining, Masson staining, and hydroxyproline quantification and then are mainly concerned with its anti-inflammatory, antiapoptotic, and antifibrotic effects.

ERCs could be located in the pulmonary circulation and play an important role. On account of a large number of blood flow through the lung and the attraction of pulmonary chemokine and inflammatory cytokines, once ERCs are injected into the vein, they would mostly be trapped and concentrated in the lung. Related studies have demonstrated that ERCs could be adsorbed to the lungs in in vivo and in vitro experiments [29].

The current disease paradigm is the ongoing AEC injury and apoptosis, deficiencies in regeneration of normal alveolar structure, aberrant lung repair, and fibroblast activation, thereby leading to progressive fibrosis. Taking into account the pathogenic role of bleomycin, we selected the second day after pulmonary fibrosis induction as the time point for ERC injection. The early ERC treatment could prevent a storm of inflammation; meanwhile, it could inhibit subsequent development of fibrosis and protect alveolar epithelial cells from injury. Thus, sequential responses of fibrosis caused by alveolar epithelial cell damage were prevented at the beginning of the disease [41, 42]. If ERCs are used for clinical treatment in the future, it may exhibit better outcome when ERCs are administered at the earlier time point after diagnosis. Although our data in this study revealed the efficacy of ERCs in alleviating lung fibrosis, the action mechanisms of ERCs in this case require further investigation. The follow-up studies will be designed to examine the antifibrosis and/or anti-inflammation of ERCs at multiple time points, so that we will understand if ERCs mainly inactivate the inflammation and/or suppress fibrogenesis.

At the same time, we speculated that ERCs could also play a crucial role by secretion of antifibrosis factors and transformation to alveolar epithelial cells while fibrosis occurs. Our experiment detected the changes of antifibrosis factors in the lung and confirmed that ERCs were indeed acting on the microenvironment of fibrosis. However, the indepth mechanism study on whether ERCs transdifferentiated into alveolar epithelial cells and thereby resulted in alleviating fibrosis is warranted.

Mice received intratracheal injection of bleomycin in accordance with accepted methods [43]. During the modeling 


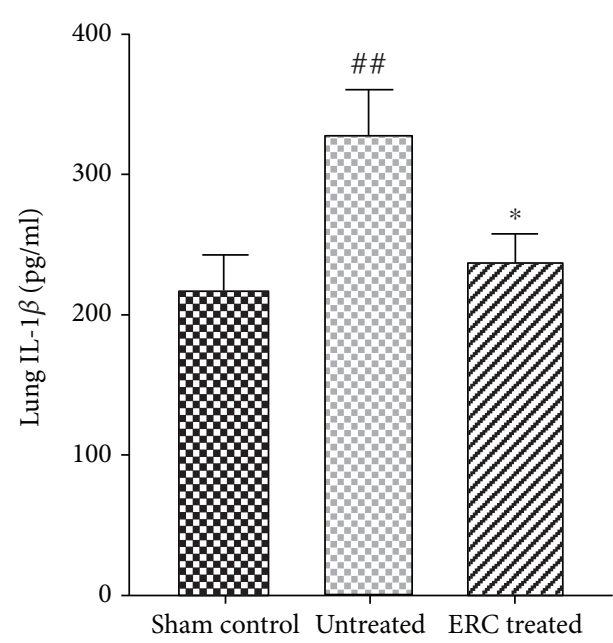

(a)

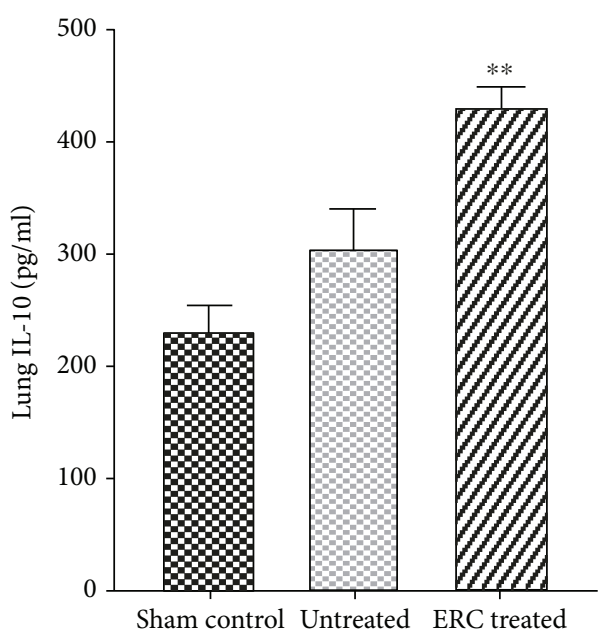

(c)

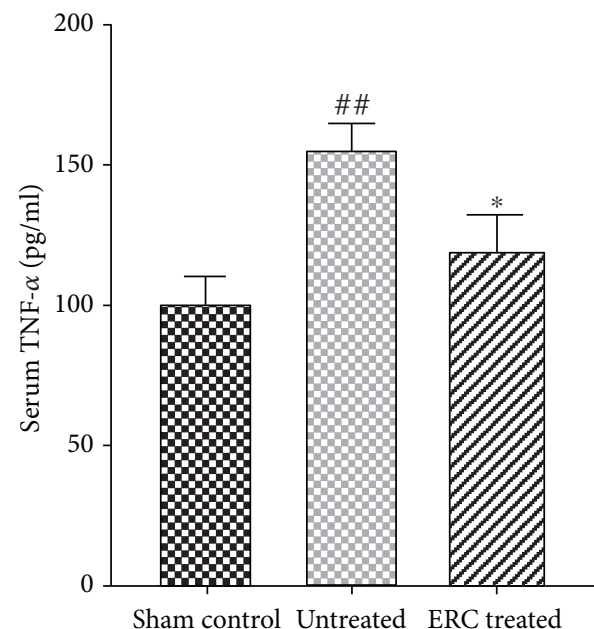

(e)

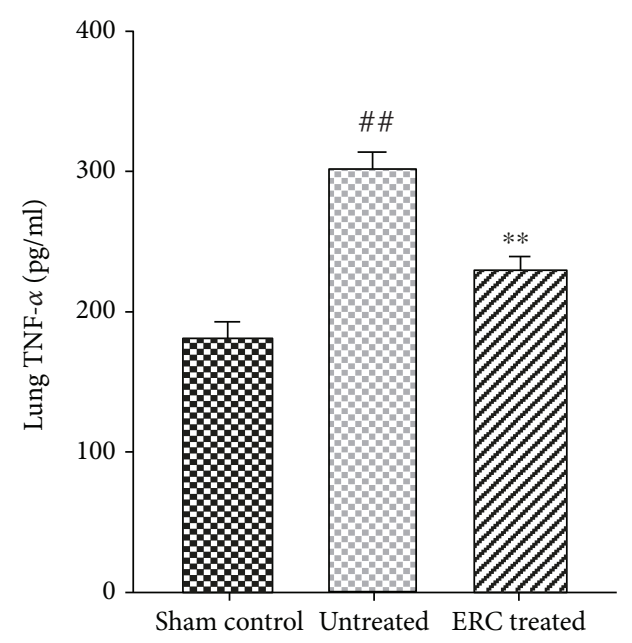

(b)

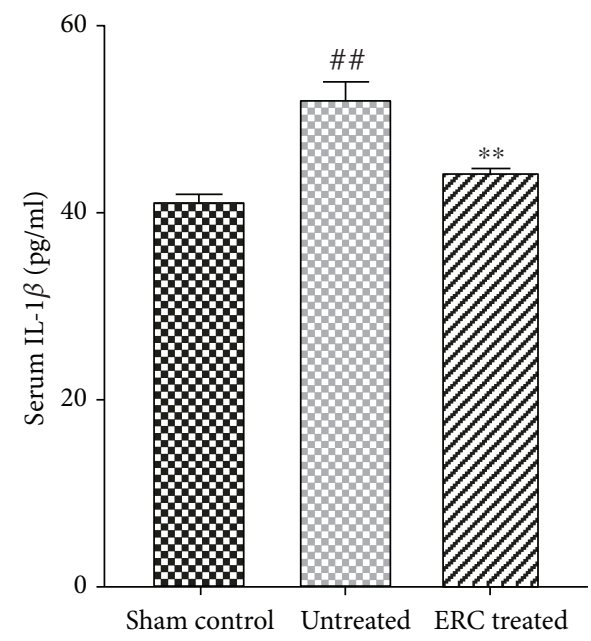

(d)

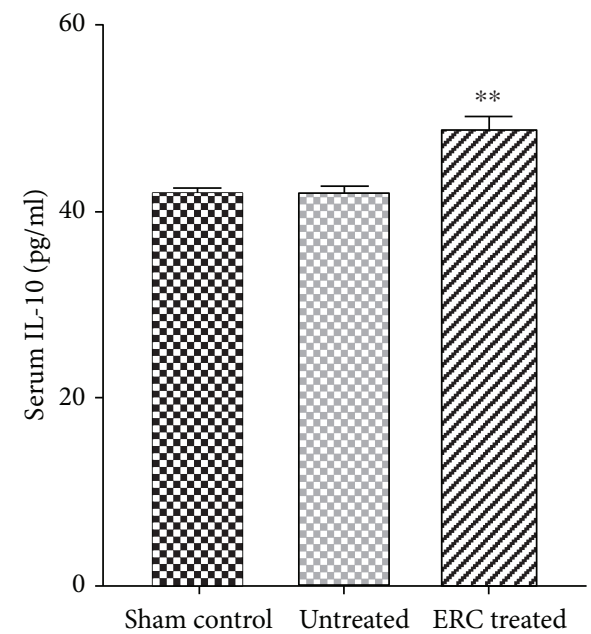

(f)

FIgURE 6: Treatment with ERCs diminishes pulmonary fibrosis by regulating cytokine profiles. The levels of IL- $1 \beta$, TNF- $\alpha$, and IL- 10 in the lung and serum were detected by ELISA kit and compared among different groups. Data indicated that ERC treatment significantly decreased the levels of IL- $1 \beta$ and TNF- $\alpha$, while it increased the level of IL-10 in both the lung and serum. Values represent mean \pm SEM. $(\# \# p<0.01$ versus the sham control group. ${ }^{*} p<0.05$ and ${ }^{* *} p<0.01$ versus the untreated group, $\left.n=6\right)$. ERCs: endometrial regenerative cells; IL-1 $\beta$ : interleukin 1 beta; TNF- $\alpha$ : tumor necrosis factor-alpha; IL-10: interleukin 10 . 


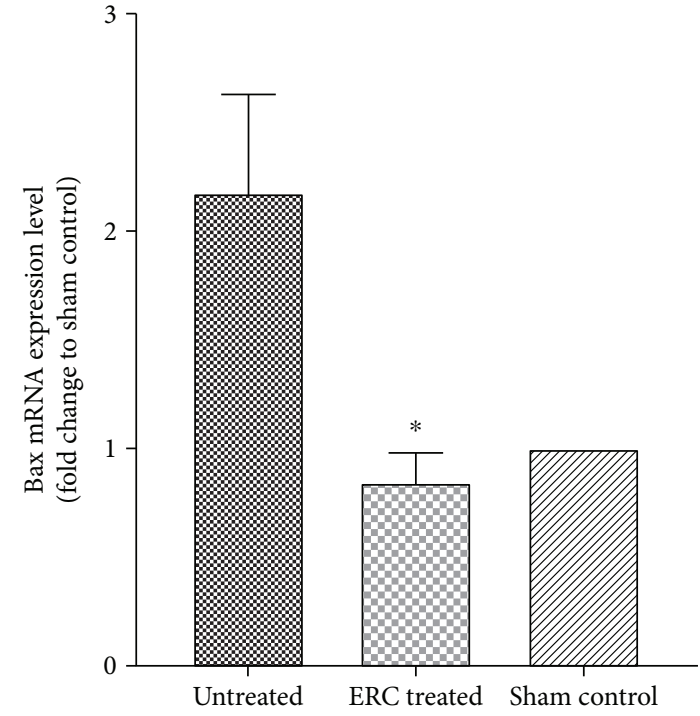

(a)

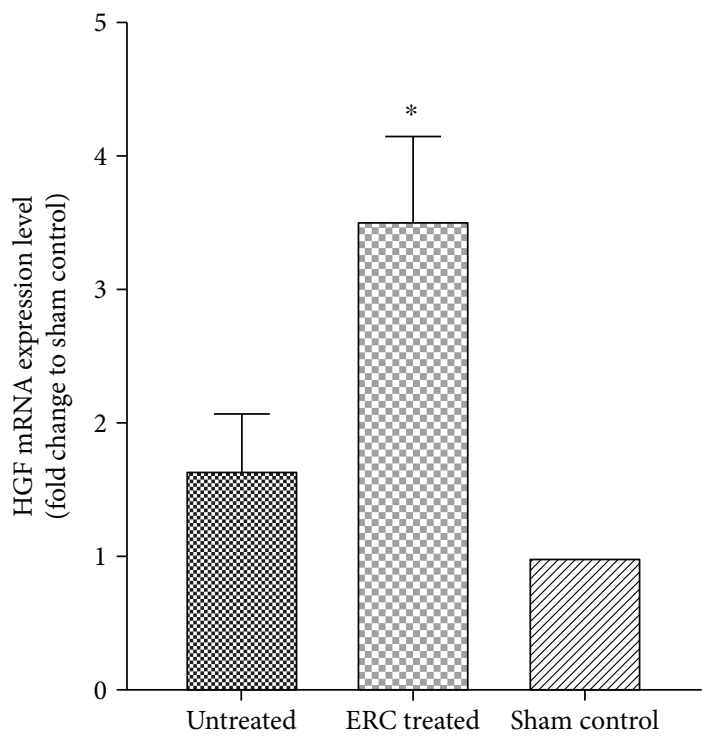

(c)

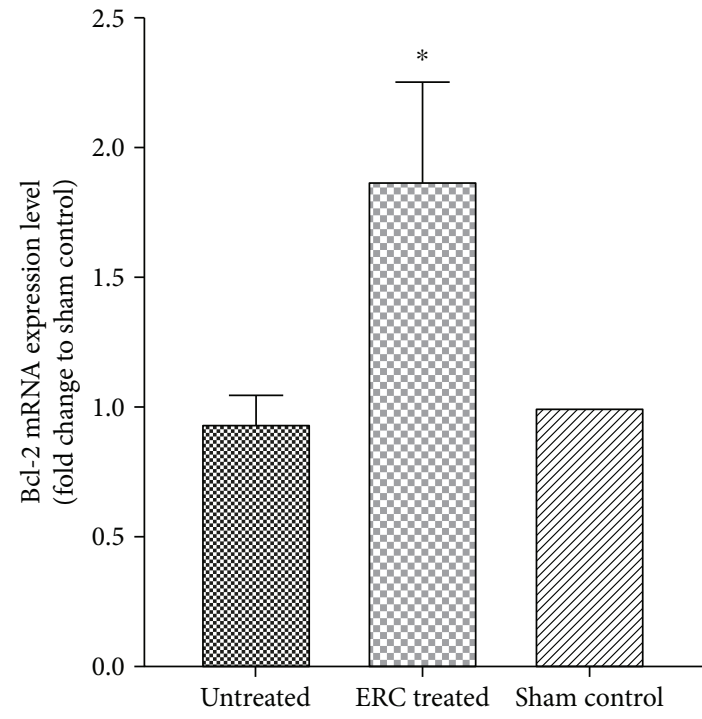

(b)

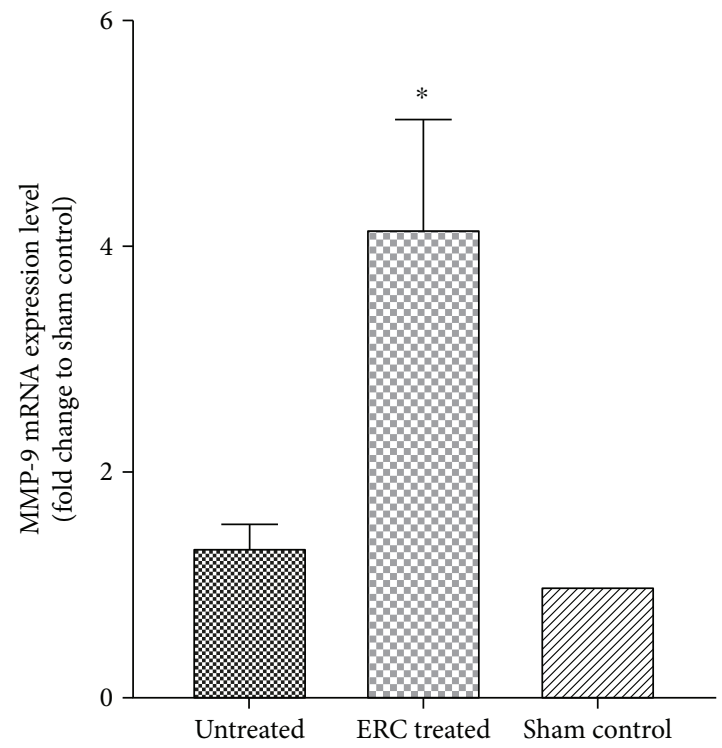

(d)

FIGURE 7: ERCs attenuate pulmonary fibrosis by upregulating antiapoptotic and antifibrotic factors in the lungs. RT-qPCR was performed to detect the relative expression levels of mRNAs of (a) Bax, (b) Bcl-2, (c) HGF, and (d) MMP-9. Data revealed that ERCs upregulate the expression of HGF, MMP-9, and Bcl-2, while downregulating the expression of Bax. Values were normalized to $\beta$-actin. Bar graphs represent mean \pm SEM of three separate experiments. $p$ values were determined by Independent-samples $t$ test. Data shown are representative of three separate experiments performed. $\left({ }^{*} p<0.05\right.$ versus the untreated group, $\left.n=6\right)$. ERCs: endometrial regenerative cells; RT-qPCR: quantitative real-time polymerase chain reaction; Bax: bcl-2-associated x protein; Bcl-2: b cell lymphoma-2; HGF: hepatocyte growth factor; MMP-9: matrix metalloproteinase 9.

process, we used insulin needles to rapidly spray $50 \mu$ liquid and then immediately rotated the mice vertically to ensure that bleomycin was distributed into each lobes of the lung. However, bleomycin was injected only in one direction into the trachea, along with the influence of breath and gravity. We cannot guarantee that pulmonary fibrosis occurs uniformly in each lung lobe, but we insisted consistent operation in every modeling process. Each group was randomly assigned and the same lung lobe was taken for the same examination to eliminate the system error. Moreover, by contrast with the untreated group, we found that ERC treatment significantly attenuated inflammatory cell infiltration, alveolar structure destruction, and fibrous tissue formation in the lung tissue. By Masson staining, we could qualitatively and intuitively discover that the fibrotic tissue was markedly reduced in the ERC-treated group. By measurement of hydroxyproline, which accounted for around $13.5 \%$ of the fiber tissue content [44], we could precisely calculate that the ERC-treated group displayed a marked reduction of fibrous tissue. 
Growing evidence indicated the role of oxidative stress in the pathophysiology of lung fibrosis $[45,46]$. In this study, we found that bleomycin induced a marked increase of lipid peroxidation as indicated by the malondialdehyde (MDA) level and this level was significantly decreased upon ERC treatment. In addition, we found that total superoxide dismutase (T-SOD), playing an important role by scavenging superoxide anion radical and protecting cells from injury, was improved by the ERC injection, when compared to that of the untreated group. These findings suggest that ERCs may play a role in protecting lung tissue against oxidative stress injury.

The underlying mechanisms of IPF is complex, including stimulating secretion and recruitment of cytokines. It has been reported that MSCs have anti-inflammatory effects in liver, kidney, and lung fibrosis [47-49]. To investigate whether ERCs play an anti-inflammatory role in the development and progression of pulmonary fibrosis, we have measured the content of IL- $1 \beta$, TNF- $\alpha$, and IL-10 in the serum and the lung tissue. Among them, IL- $1 \beta$ is a proinflammatory regulatory factor involved in the regulation of inflammation and fibrosis, which is crucial in the early stage of pulmonary fibrosis $[50,51]$. IL- $1 \beta$ has been previously shown to hamper silica-induced inflammation and fibrosis by inhibiting TNF- $\alpha$, MCP- 1 , TGF- $\beta 1$, collagen I, and fibronectin mediators and modulating the Th1/Th2 balance [52]. Besides, related researches have revealed that $\mathrm{WNT} / \beta$-catenin signaling can induce IL- $1 \beta$ expression by alveolar epithelial cells in pulmonary fibrosis [53]. Then we could infer that, by downregulation of IL- $1 \beta$, ERCs might provide a mild microenvironment for tissue repair. This agrees with the hypothesis that stem cells can ameliorate the microenvironment of the injury site $[54,55]$. Cooperating with IL- $1 \beta$, TNF- $\alpha$ also plays a synergistic role in promoting inflammatory cell adhesion, releasing inflammatory mediators, and enhancing lung injury.

Meanwhile, previous studies have shown that Ad-MSCs have autocrine cytokine IL-10 function, which can effectively prevent alveolar macrophages from releasing a variety of inflammatory and profibrosis factors, thereby preventing the cascade secretion of cytokines [56]. High levels of IL-10 also inhibit production and activation of TGF- $\beta$, thereby inhibiting the occurrence of inflammatory responses $[57,58]$. In the present study, the level of IL-10 in the serum and the lung was elevated after ERC treatment, suggesting that ERCs might protect the mice from pulmonary fibrosis by upregulating IL-10 both locally and systematically.

Multiple lines of evidence have revealed that apoptosis and injury of alveolar epithelium play a primary role in pulmonary fibrosis, then recruiting cytokines, inflammatory cells, and fibrosis factors, thus leading to microenvironment disorder $[41,59,60]$. Bax, one of the most important apoptosis genes, encoded Bax protein which can form heterodimer with Bcl-2 or be homologous with itself, participating in the regulation of apoptosis. The present experiment revealed that the mRNA expression level of Bax/Bcl-2 in the ERC-treated group was significantly lower than that in the untreated group. Thus, we conclude that ERCs might protect alveolar epithelium cells from damage by antiapoptosis.
The vital role of TGF- $\beta$ in promoting fibrosis has been proven in numerous studies $[9,61,62]$. Cells secreting TGF- $\beta$ are much like alveolar macrophages, epithelial cells, and fibroblasts. Among them, alveolar macrophages and epithelial cells may be the major source of TGF- $\beta[63,64]$. When tissue damage and infection occur, the microenvironment of the lung is broken and TGF- $\beta$ begins to function as a central regulator [65]. Its main roles include (1) providing chemotactic effects on monocytes and macrophages and promoting the expression of cytokines related to pulmonary fibrosis such as TNF- $\alpha$, IL-1, IL-6, and PDGF [66]; (2) inducing epithelial-mesenchymal transition in alveolar epithelial cells $[61,67]$; (3) promoting the migration, proliferation, differentiation of fibroblasts, and deposition of extracellular matrix [68]; and (4) protecting the stability of the extracellular matrix without degradation. However, through the localization and qualitative analysis by immunohistochemistry in this study, the expression of TGF- $\beta$ in the ERC-treated group was significantly lower than that in the untreated group. It reminds us that ERCs may play a role by potentially secreting cytokine or directly contacting macrophages and alveolar epithelial cells in the lung tissue and then inhibiting their secretion of TGF- $\beta$. Thus, lower expression of TGF- $\beta$ mediated by ERC treatment helped in cutting off the source of fibrogenic factors, reducing pulmonary inflammatory cell aggregation and preventing the occurrence of EMT and thereby relieving pulmonary fibrosis.

We have also detected HGF and MMP-9 mRNA levels in lung tissue, and found that ERC treatment did increase the expression of these two antifibrosis factors. It is worth noting that HGF was once considered to be a hepatotropic factor; it is a newly discovered mesenchymal-derived multifunctional growth factor [69]. There is evidence that C-met, specific receptor of HGF, expresses in alveolar epithelial cells [70]. These results indicate that HGF is targeted to adjacent epithelial cells, regulating their proliferation and differentiation and thus promoting the structural remodeling of alveolar epithelium [70]. Moreover, matrix metalloproteinases (MMPs) are proteinases that can degrade all components of the extracellular matrix and numerous nonmatrix proteins $[71,72]$. Among which, MMP-9 is one of the most significantly overexpressed proteins in the lungs of patients with IPF [73]. By detecting HGF and MMP-9, we have provided a potential target for ERCs to alleviate lung fibrosis.

In summary, these findings from our study indicate that human ERC-based therapy can attenuate bleomycininduced pulmonary fibrosis in mice. Although the results are inspiring and encouraging, an in-depth study in investigating the signaling pathway and the interaction of microenvironment in ERC-mediated lung protection is warranted.

\section{Conclusions}

In this study, we for the first time have demonstrated that human ERCs, a new type of regenerative stem cells, have immunosuppressive and antifibrosis properties and play an important role in attenuation of bleomycin-induced pulmonary fibrosis in mice. We found that ERCs are effective in alleviating fibrosis, decreasing hydroxyproline content and 
fibrosis initiation factor TGF- $\beta$ and upregulating antiapoptosis gene Bax and antifibrosis factors of HGF and MMP-1, while reducing the serum and lung homogenate of IL- $1 \beta$ and TNF- $\alpha$ and increasing those of IL-10. Taken together, the results generated in this study form a foundation for further study of ERC mechanism acting on pulmonary fibrosis and provide a rationale for the use of ERCs in clinical treatment.

\section{Conflicts of Interest}

The authors declare that there is no conflict of interest regarding the publication of this article.

\section{Authors' Contributions}

Yiming Zhao, Xu Lan, and Yong Wang contributed equally to this work. Yiming Zhao, Xu Lan, and Yong Wang conceived, designed and implemented the research, performed data analysis and interpretation, and wrote the manuscript. Xiaoxi Xu, Shanzheng Lu, Xiang Li, Baoren Zhang, and Ganggang Shi performed the research and data analysis. Gu Xiangying provided the study material and administrative support. Caigan Du performed data analysis and manuscript writing. Hao Wang performed conception, provided financial and administrative support, helped in manuscript writing, and gave final approval of the manuscript. All authors read and approved the final manuscript.

\section{Acknowledgments}

The authors are grateful to Dr. Hongyue Li for his conduct in experimental implementation and data review. This work was supported by grants to Hao Wang from the National Natural Science Foundation of China (nos. 81471584 and 81273257), Tianjin Application Basis and Cutting-Edge Technology Research Grant (no. 14JCZDJC35700), Li Jieshou Intestinal Barrier Research Special Fund (no. LJS_201412), and Tianjin Medical University Talent Fund.

\section{References}

[1] T. E. King Jr., A. Pardo, and M. Selman, "Idiopathic pulmonary fibrosis," The Lancet, vol. 378, no. 9807, pp. 1949-1961, 2011.

[2] P. F. Mercer and R. C. Chambers, "Innate immune signaling and stem cell renewal in idiopathic pulmonary fibrosis," Nature Medicine, vol. 22, no. 11, pp. 1210-1212, 2016.

[3] M. Reddy, L. Fonseca, S. Gowda, B. Chougule, A. Hari, and S. Totey, "Human adipose-derived mesenchymal stem cells attenuate early stage of bleomycin induced pulmonary fibrosis: comparison with pirfenidone," International Journal of Stem Cells, vol. 9, no. 2, pp. 192-206, 2016.

[4] R. C. Chambers and P. F. Mercer, "Mechanisms of alveolar epithelial injury, repair, and fibrosis," Annals of the American Thoracic Society, vol. 12, Supplement 1, pp. S16-S20, 2015.

[5] J. Liang, Y. Zhang, T. Xie et al., "Hyaluronan and TLR4 promote surfactant-protein-C-positive alveolar progenitor cell renewal and prevent severe pulmonary fibrosis in mice," Nature Medicine, vol. 22, no. 11, pp. 1285-1293, 2016.

[6] G. Bagnato and S. Harari, "Cellular interactions in the pathogenesis of interstitial lung diseases," European Respiratory Review, vol. 24, no. 135, pp. 102-114, 2015.

[7] P. J. Wolters, H. R. Collard, and K. D. Jones, "Pathogenesis of idiopathic pulmonary fibrosis," Annual Review of Pathology, vol. 9, no. 1, pp. 157-179, 2014.

[8] D. Sheppard, "Epithelial-mesenchymal interactions in fibrosis and repair. Transforming growth factor- $\beta$ activation by epithelial cells and fibroblasts," Annals of the American Thoracic Society, vol. 12, Supplement 1, pp. S21-S23, 2015.

[9] A. Biernacka, M. Dobaczewski, and N. G. Frangogiannis, "TGF- $\beta$ signaling in fibrosis," Growth Factors, vol. 29, no. 5, pp. 196-202, 2011.

[10] V. Poletti, C. Ravaglia, and S. Tomassetti, "Pirfenidone for the treatment of idiopathic pulmonary fibrosis," Expert Review of Respiratory Medicine, vol. 8, no. 5, pp. 539-545, 2014.

[11] L. Knüppel, Y. Ishikawa, M. Aichler et al., "A novel Antifibrotic mechanism of nintedanib and pirfenidone. Inhibition of collagen fibril assembly," American Journal of Respiratory Cell and Molecular Biology, vol. 57, no. 1, pp. 77-90, 2017.

[12] M. A. Antunes, J. G. Laffey, P. Pelosi, and P. R. M. Rocco, "Mesenchymal stem cell trials for pulmonary diseases," Journal of Cellular Biochemistry, vol. 115, no. 6, pp. 1023-1032, 2014.

[13] A. C. Inamdar and A. A. Inamdar, "Mesenchymal stem cell therapy in lung disorders: pathogenesis of lung diseases and mechanism of action of mesenchymal stem cell," Experimental Lung Research, vol. 39, no. 8, pp. 315-327, 2013.

[14] Y. W. Lan, K. B. Choo, C. M. Chen et al., "Hypoxia-preconditioned mesenchymal stem cells attenuate bleomycin-induced pulmonary fibrosis," Stem Cell Research \& Therapy, vol. 6, no. 1, p. 97, 2015.

[15] Y.-W. Lan, S. M. Theng, T. T. Huang et al., "Oncostatin Mpreconditioned mesenchymal stem cells alleviate bleomycininduced pulmonary fibrosis through paracrine effects of the hepatocyte growth factor," Stem Cells Translational Medicine, vol. 6, no. 3, pp. 1006-1017, 2017.

[16] J. Yang and Z. Jia, "Cell-based therapy in lung regenerative medicine," Regenerative Medicine Research, vol. 2, no. 1, p. 7, 2014.

[17] K. M. Akram, S. Samad, M. A. Spiteri, and N. R. Forsyth, "Mesenchymal stem cells promote alveolar epithelial cell wound repair in vitro through distinct migratory and paracrine mechanisms," Respiratory Research, vol. 14, no. 1, p. 9, 2013.

[18] M. Hayes, G. F. Curley, C. Masterson, J. Devaney, D. O’Toole, and J. G. Laffey, "Mesenchymal stromal cells are more effective than the MSC secretome in diminishing injury and enhancing recovery following ventilator-induced lung injury," Intensive Care Medicine Experimental, vol. 3, no. 1, p. 29, 2015.

[19] M. K. Glassberg, J. Minkiewicz, R. L. Toonkel et al., “Allogeneic human mesenchymal stem cells in patients with idiopathic pulmonary fibrosis via intravenous delivery (AETHER): a phase I safety clinical trial," Chest, vol. 151, no. 5, pp. 971-981, 2017.

[20] P. Barcellos-de-Souza, V. Gori, F. Bambi, and P. Chiarugi, "Tumor microenvironment: bone marrow-mesenchymal stem cells as key players," Biochimica et Biophysica Acta, vol. 1836, no. 2, pp. 321-335, 2013. 
[21] A. E. Karnoub, A. B. Dash, A. P. Vo et al., "Mesenchymal stem cells within tumour stroma promote breast cancer metastasis," Nature, vol. 449, no. 7162, pp. 557-563, 2007.

[22] X. Meng, T. E. Ichim, J. Zhong et al., "Endometrial regenerative cells: a novel stem cell population," Journal of Translational Medicine, vol. 5, no. 1, p. 57, 2007.

[23] M. P. Murphy, H. Wang, A. N. Patel et al., "Allogeneic endometrial regenerative cells: an "off the shelf solution" for critical limb ischemia?," Journal of Translational Medicine, vol. 6, no. 1, p. $45,2008$.

[24] X. Xu, X. Li, X. Gu et al., "Prolongation of cardiac allograft survival by endometrial regenerative cells: focusing on B-cell responses," Stem Cells Translational Medicine, vol. 6, no. 3, pp. 778-787, 2017.

[25] P. Sun, J. Liu, W. Li et al., "Human endometrial regenerative cells attenuate renal ischemia reperfusion injury in mice," Journal of Translational Medicine, vol. 14, no. 1, p. 28, 2016.

[26] Y. Lv, X. Xu, B. Zhang et al., "Endometrial regenerative cells as a novel cell therapy attenuate experimental colitis in mice," Journal of Translational Medicine, vol. 12, no. 1, p. 344, 2014.

[27] H. Drago, G. H. Marín, F. Sturla et al., "The next generation of burns treatment: intelligent films and matrix, controlled enzymatic debridement, and adult stem cells," Transplantation Proceedings, vol. 42, no. 1, pp. 345-349, 2010.

[28] S. Lu, G. Shi, X. Xu et al., "Human endometrial regenerative cells alleviate carbon tetrachloride-induced acute liver injury in mice," Journal of Translational Medicine, vol. 14, no. 1, p. 300, 2016.

[29] B. Xiang, L. Chen, X. Wang, Y. Zhao, Y. Wang, and C. Xiang, "Transplantation of menstrual blood-derived mesenchymal stem cells promotes the repair of LPS-induced acute lung injury," International Journal of Molecular Sciences, vol. 18, no. $4,2017$.

[30] X. Du, Q. Yuan, Y. Qu, Y. Zhou, and J. Bei, "Endometrial mesenchymal stem cells isolated from menstrual blood by adherence," Stem Cells International, vol. 2016, Article ID 3573846, 8 pages, 2016.

[31] N. Hida, N. Nishiyama, S. Miyoshi et al., "Novel cardiac precursor-like cells from human menstrual blood-derived mesenchymal cells," Stem Cells, vol. 26, no. 7, pp. 1695-1704, 2008.

[32] S. H. Yu, L. J. Liu, B. Lv et al., "Inhibition of bleomycininduced pulmonary fibrosis by bone marrow-derived mesenchymal stem cells might be mediated by decreasing MMP9, TIMP-1, INF- $\gamma$ and TGF- $\beta$," Cell Biochemistry and Function, vol. 33, no. 6, pp. 356-365, 2015.

[33] M. Zhou, D.-L. Chen, T. Jiang, Y.-M. Feng, and X.-L. Han, "Effects of bone marrow-derived mesenchymal stem cells transfected with survivin on pulmonary fibrosis in mice," Experimental and Therapeutic Medicine, vol. 10, no. 5, pp. 1857-1864, 2015.

[34] E. M. Fikry, M. M. Safar, W. A. Hasan, H. M. Fawzy, and E. E. D. S. el-Denshary, "Bone marrow and adipose-derived mesenchymal stem cells alleviate methotrexate-induced pulmonary fibrosis in rat: comparison with dexamethasone," Journal of Biochemical and Molecular Toxicology, vol. 29, no. 7, pp. 321-329, 2015.

[35] T. Ashcroft, J. M. Simpson, and V. Timbrell, "Simple method of estimating severity of pulmonary fibrosis on a numerical scale," Journal of Clinical Pathology, vol. 41, no. 4, pp. 467470, 1988.
[36] R.-H. Hübner, W. Gitter, N. Eddine el Mokhtari et al., "Standardized quantification of pulmonary fibrosis in histological samples," BioTechniques, vol. 44, no. 4, pp. 507-517, 2008.

[37] J. P. Hutchinson, T. M. McKeever, A. W. Fogarty, V. Navaratnam, and R. B. Hubbard, "Increasing global mortality from idiopathic pulmonary fibrosis in the twenty-first century," Annals of the American Thoracic Society, vol. 11, no. 8, pp. 1176-1185, 2014.

[38] J. Hutchinson, A. Fogarty, R. Hubbard, and T. McKeever, "Global incidence and mortality of idiopathic pulmonary fibrosis: a systematic review," The European Respiratory Journal, vol. 46, no. 3, pp. 795-806, 2015.

[39] R. G. Edwards, "Stem cells today: B1. Bone marrow stem cells," Reproductive Biomedicine Online, vol. 9, no. 5, pp. 541-583, 2004.

[40] D. T. Harris, M. Badowski, N. Ahmad, and M. A. Gaballa, "The potential of cord blood stem cells for use in regenerative medicine," Expert Opinion on Biological Therapy, vol. 7, no. 9, pp. 1311-1322, 2007.

[41] D. F. Zoz, W. E. Lawson, and T. S. Blackwell, "Idiopathic pulmonary fibrosis: a disorder of epithelial cell dysfunction," The American Journal of the Medical Sciences, vol. 341, no. 6, pp. 435-438, 2011.

[42] R. P. Naikawadi, S. Disayabutr, B. Mallavia et al., "Telomere dysfunction in alveolar epithelial cells causes lung remodeling and fibrosis," JCI Insight, vol. 1, no. 14, article e86704, 2016.

[43] E. D. Manali, C. Moschos, C. Triantafillidou et al., "Static and dynamic mechanics of the murine lung after intratracheal bleomycin," BMC Pulmonary Medicine, vol. 11, no. 1, p. 33, 2011.

[44] R. Neuman and M. Logan, "The determination of hydroxyproline," The Journal of Biological Chemistry, vol. 184, no. 1, pp. 299-306, 1950.

[45] V. L. Kinnula, C. L. Fattman, R. J. Tan, and T. D. Oury, "Oxidative stress in pulmonary fibrosis: a possible role for redox modulatory therapy," American Journal of Respiratory and Critical Care Medicine, vol. 172, no. 4, pp. 417-422, 2005.

[46] P. Cheresh, S. J. Kim, S. Tulasiram, and D. W. Kamp, "Oxidative stress and pulmonary fibrosis," Biochimica et Biophysica Acta, vol. 1832, no. 7, pp. 1028-1040, 2013.

[47] Y. W. Eom, K. Y. Shim, and S. K. Baik, "Mesenchymal stem cell therapy for liver fibrosis," The Korean Journal of Internal Medicine, vol. 30, no. 5, pp. 580-589, 2015.

[48] H. J. Wu, W. H. Yiu, R. X. Li et al., "Mesenchymal stem cells modulate albumin-induced renal tubular inflammation and fibrosis," PLoS One, vol. 9, no. 3, article e90883, 2014.

[49] Q. Shen, B. Chen, Z. Xiao et al., "Paracrine factors from mesenchymal stem cells attenuate epithelial injury and lung fibrosis," Molecular Medicine Reports, vol. 11, no. 4, pp. 2831-2837, 2015.

[50] A. E. Postlethwaite, R. Raghow, G. P. Stricklin, H. Poppleton, J. M. Seyer, and A. H. Kang, "Modulation of fibroblast functions by interleukin 1: increased steady-state accumulation of type I procollagen messenger RNAs and stimulation of other functions but not chemotaxis by human recombinant interleukin 1 alpha and beta," Journal of Cell Biology, vol. 106, no. 2, pp. 311-318, 1988.

[51] P. Gasse, C. Mary, I. Guenon et al., "IL-1R1/MyD88 signaling and the inflammasome are essential in pulmonary inflammation and fibrosis in mice," The Journal of Clinical Investigation, vol. 117, no. 12, pp. 3786-3799, 2007. 
[52] J. Guo, N. Gu, J. Chen et al., "Neutralization of interleukin-1 beta attenuates silica-induced lung inflammation and fibrosis in C57BL/6 mice," Archives of Toxicology, vol. 87, no. 11, pp. 1963-1973, 2013.

[53] V. Aumiller, N. Balsara, J. Wilhelm, A. Gunther, and M. Konigshoff, "WNT/ $\beta$-catenin signaling induces IL- $1 \beta$ expression by alveolar epithelial cells in pulmonary fibrosis," American Journal of Respiratory Cell and Molecular Biology, vol. 49, no. 1, pp. 96-104, 2013.

[54] A. I. Caplan, "MSCs: the sentinel and safe-guards of injury," Journal of Cellular Physiology, vol. 231, no. 7, pp. 1413-1416, 2016.

[55] I. U. Schraufstatter, R. G. Discipio, and S. Khaldoyanidi, "Mesenchymal stem cells and their microenvironment," Frontiers in Bioscience, vol. 16, no. 1, pp. 2271-2288, 2011.

[56] H. D. Li, Q. X. Zhang, Z. Mao, X. J. Xu, N. Y. Li, and H. Zhang, "Exogenous interleukin-10 attenuates hyperoxia-induced acute lung injury in mice," Experimental Physiology, vol. 100, no. 3, pp. 331-340, 2015.

[57] K. Nakagome, M. Dohi, K. Okunishi, R. Tanaka, J. Miyazaki, and K. Yamamoto, "In vivo IL-10 gene delivery attenuates bleomycin induced pulmonary fibrosis by inhibiting the production and activation of TGF- $\beta$ in the lung," Thorax, vol. 61, no. 10, pp. 886-894, 2006.

[58] E. Sziksz, D. Pap, R. Lippai et al., "Fibrosis related inflammatory mediators: role of the IL-10 cytokine family," Mediators of Inflammation, vol. 2015, Article ID 764641, 15 pages, 2015.

[59] M. Plataki, A. V. Koutsopoulos, K. Darivianaki, G. Delides, N. M. Siafakas, and D. Bouros, "Expression of apoptotic and antiapoptotic markers in epithelial cells in idiopathic pulmonary fibrosis," Chest, vol. 127, no. 1, pp. 266-274, 2005.

[60] R. Wang, C. Ramos, I. Joshi et al., "Human lung myofibroblast-derived inducers of alveolar epithelial apoptosis identified as angiotensin peptides," The American Journal of Physiology, vol. 277, 6, Part 1, pp. L1158-L1164, 1999.

[61] B. C. Willis and Z. Borok, "TGF- $\beta$-induced EMT: mechanisms and implications for fibrotic lung disease," American Journal of Physiology Lung Cellular and Molecular Physiology, vol. 293, no. 3, pp. L525-L534, 2007.

[62] E. M. MacDonald and R. D. Cohn, "TGF $\beta$ signaling: its role in fibrosis formation and myopathies," Current Opinion in Rheumatology, vol. 24, no. 6, pp. 628-634, 2012.

[63] A. N. Lekkerkerker, J. Aarbiou, T. van Es, and R. A. J. Janssen, "Cellular players in lung fibrosis," Current Pharmaceutical Design, vol. 18, no. 27, pp. 4093-4102, 2012.

[64] M. Ono, S. Ohkouchi, M. Kanehira et al., "Mesenchymal stem cells correct inappropriate epithelial-mesenchyme relation in pulmonary fibrosis using stanniocalcin-1," Molecular Therapy, vol. 23, no. 3, pp. 549-560, 2015.

[65] D. Sheppard, "Transforming growth factor beta: a central modulator of pulmonary and airway inflammation and fibrosis," Proceedings of the American Thoracic Society, vol. 3, no. 5, pp. 413-417, 2006.

[66] U. Bartram and C. P. Speer, "The role of transforming growth factor beta in lung development and disease," Chest, vol. 125, no. 2, pp. 754-765, 2004.

[67] H. A. Chapman, "Epithelial-mesenchymal interactions in pulmonary fibrosis," Annual Review of Physiology, vol. 73, no. 1, pp. 413-435, 2011.

[68] K. Omori, N. Hattori, T. Senoo et al., "Inhibition of plasminogen activator Inhibitor-1 attenuates transforming growth factor- $\beta$-dependent epithelial mesenchymal transition and differentiation of fibroblasts to myofibroblasts," PLoS One, vol. 11, no. 2, article e0148969, 2016.

[69] S. Chakraborty, P. Chopra, A. Hak, S. G. Dastidar, and A. Ray, "Hepatocyte growth factor is an attractive target for the treatment of pulmonary fibrosis," Expert Opinion on Investigational Drugs, vol. 22, no. 4, pp. 499-515, 2013.

[70] R. A. M. Panganiban and R. M. Day, "Hepatocyte growth factor in lung repair and pulmonary fibrosis," Acta Pharmacologica Sinica, vol. 32, no. 1, pp. 12-20, 2011.

[71] V. J. Craig, L. Zhang, J. S. Hagood, and C. A. Owen, "Matrix metalloproteinases as therapeutic targets for idiopathic pulmonary fibrosis," American Journal of Respiratory Cell and Molecular Biology, vol. 53, no. 5, pp. 585-600, 2015.

[72] R. C. A. Dancer, A. M. Wood, and D. R. Thickett, "Metalloproteinases in idiopathic pulmonary fibrosis," The European Respiratory Journal, vol. 38, no. 6, pp. 1461-1467, 2011.

[73] J. J. Atkinson and R. M. Senior, "Matrix metalloproteinase-9 in lung remodeling," American Journal of Respiratory Cell and Molecular Biology, vol. 28, no. 1, pp. 12-24, 2003. 


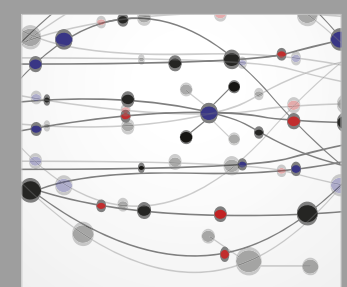

The Scientific World Journal
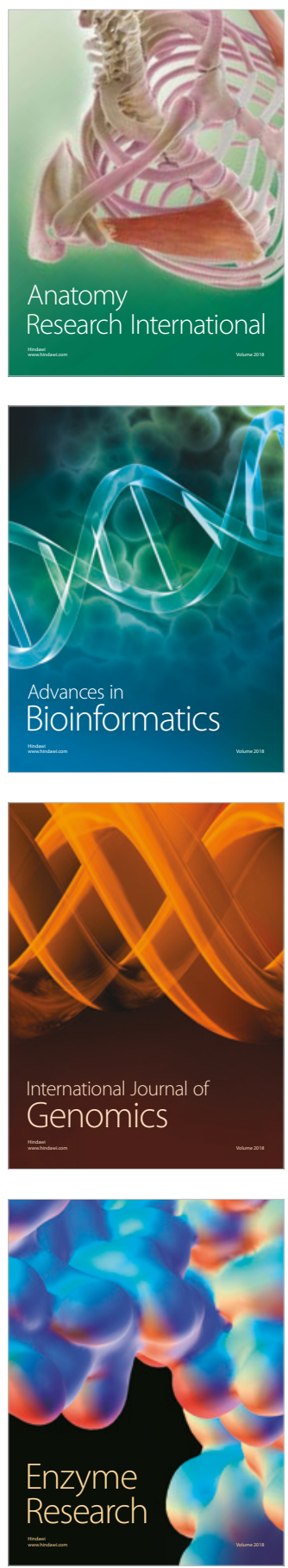
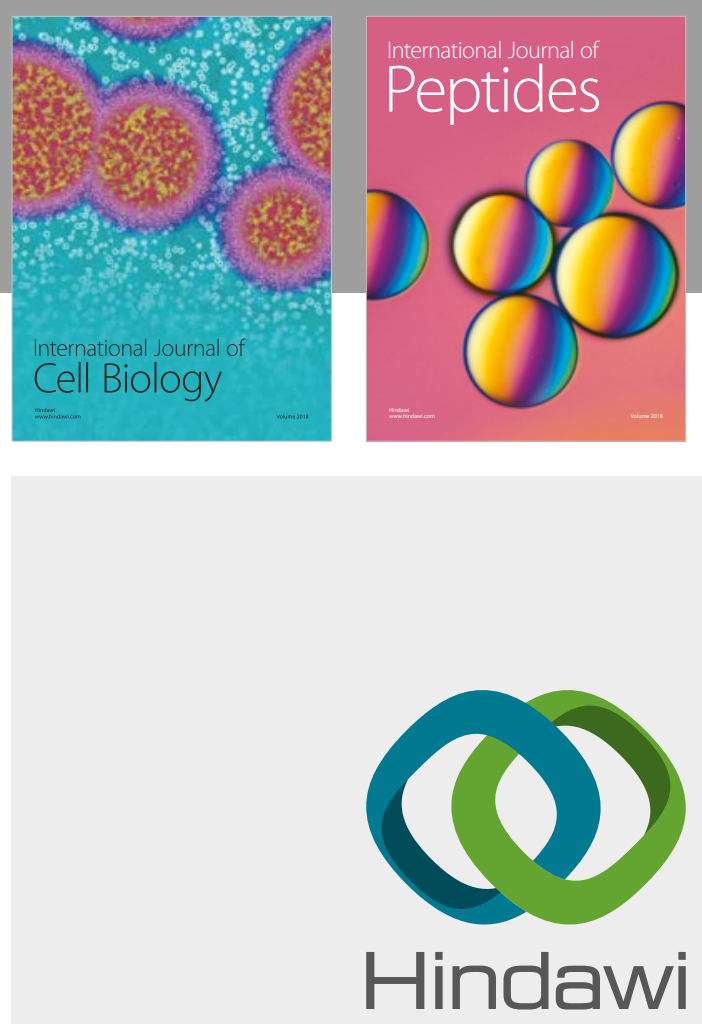

Submit your manuscripts at

www.hindawi.com
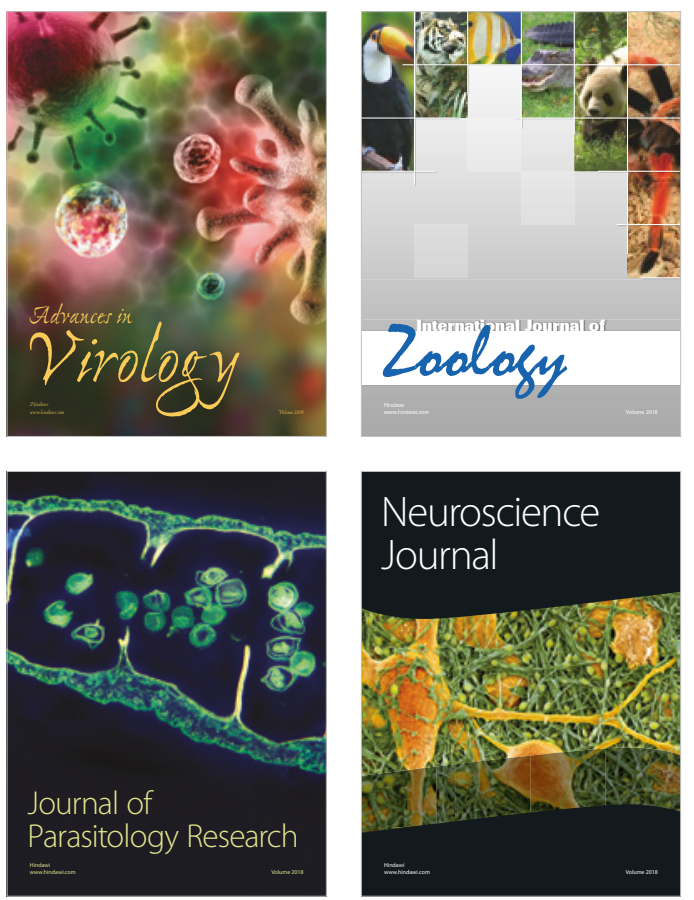
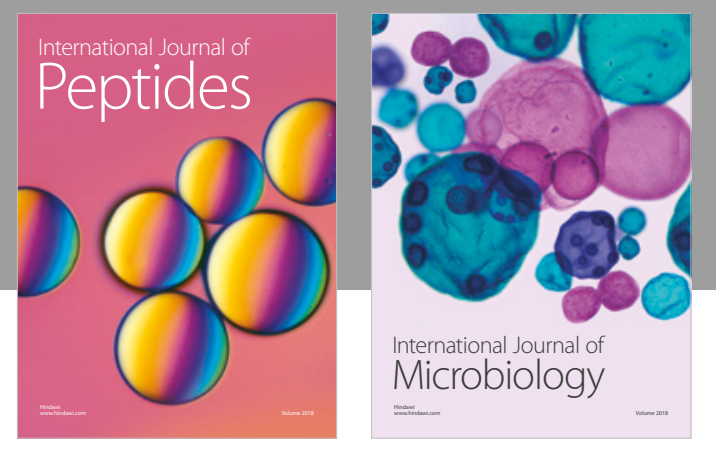

nternational Journal of Microbiology
Journal of
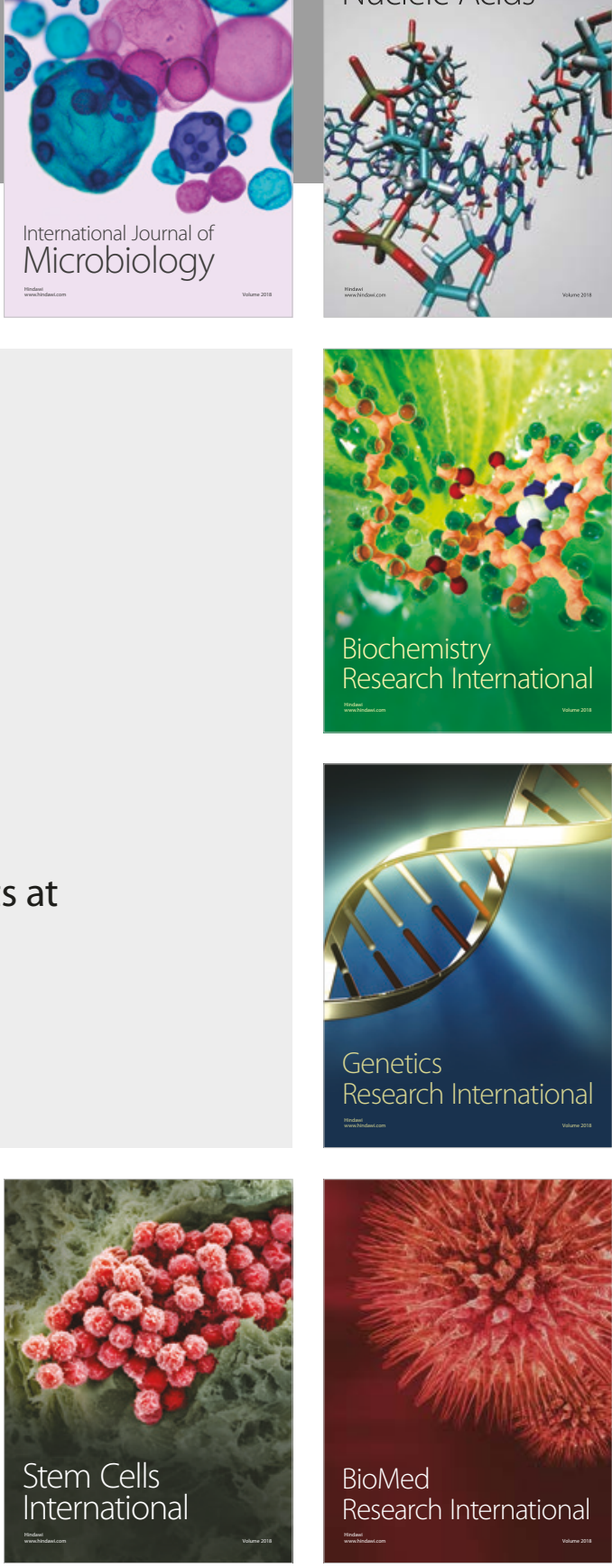
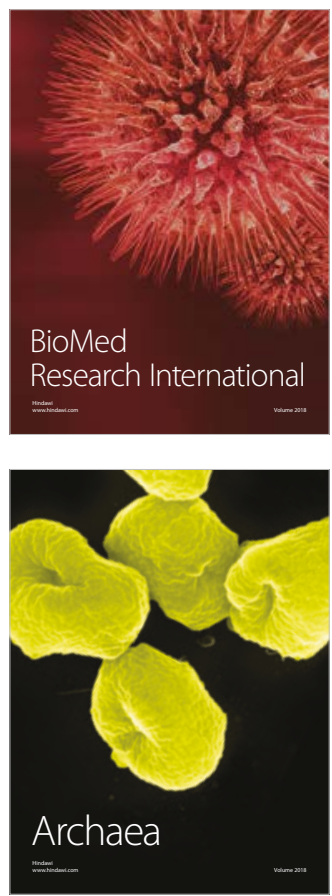